MATEC Web of Conferences 19, 01010 (2014)

DOI: $10.1051 /$ matecconf/ 20141901010

(C) Owned by the authors, published by EDP Sciences, 2014

\title{
Heat and mass transfer in two-phase flow motion in minichannel under variable heating
}

\author{
Evgenii S. Chachilo ${ }^{1,}$, Michael N. Grehov ${ }^{1}$, Dmitrii V. Feoktistov ${ }^{1}$ \\ ${ }^{1}$ Department of Theoretical and Industrial Heat Systems Engineering, Institute of Power Engineering, Tomsk \\ Polytechnic University, 634050, Tomsk, Russia
}

\begin{abstract}
Experimental studying the effect of temperature on evaporation dynamics of the stationary horizontal liquid layer is presented. The average evaporation flow rate of liquid layer (ethanol) by the gas flow (air) has been calculated using two independent methods. The dependence of the evaporation flow rate from the temperature has been obtained. According to the analysis of the results it was found that the dependence is nonlinear and described by an exponential function.
\end{abstract}

\section{Introduction}

Nowadays there is a rapid development of heat exchange systems with mini sizes that can divert heat fluxes of up to $1000 \mathrm{~W} / \mathrm{cm}^{2}$ [1]. Such devices are used for cooling of microelectronic equipment [1-3], in particular at the development of miniature heat pipes [3], in the fuel cell membrane [3], evaporator condensing units of spacecraft heat setting systems [3-4], in devices with micro channels for separation of two-phase flow under the earth and microgravity, in cryogenic cooling systems of satellites [6].

Scientific bases of heat and mass transfer [6-9] in two-phase flow do not provide predictive modeling of the heat exchange systems with small dimensions.

The purpose of present work is the investigation of the effect of liquid and gas temperatures on evaporation dynamics of the stationary horizontal liquid layer.

\section{Research technique}

The present experimental investigation is performed using an experimental setup (Fig.1) consisting of the test cell 1 , gas 2 and liquid 3 supply circuits, thermal stabilization system 4 , test-and-measurement 5 and Schlieren systems 6.

As the gas which arrives to the test cell we use air. Air induction was carried out from the environment and controlled by the flow controller 7. The peristaltic pump 8 is used for pre-filling of the cell with the working liquid (ethanol $95 \%$ part by volume) at the beginning of the experiment and controlling interface "gas - liquid". The gas-vapor mixture flows to the outlet of the test cell where its flow rate is measured by the flow meter 9 Pressure of the gas phase inside the test cell is measured by the pressure sensor 10. Temperatures of the gas 11 and the gas-vapor mixture 12 are measured at the inlet/outlet of the test cell. Temperature of the test cell is controlled by distilled water which is pumped through special channels in the test cell by applying the thermostatic bath 13 . The inlet temperature of the working liquid is assumed to be equal to temperature of the piston, because the

This is an Open Access article distributed under the terms of the Creative Commons Attribution License 4.0, which permits unrestricted use, distribution, and reproduction in any medium, provided the original work is properly cited. 


\section{MATEC Web of Conferences}

piston is made from a massive copper block having the high thermal conductivity. The temperature of the piston is given by the Peltier thermoelectric module 14 . Thus, the temperature difference between the liquid and the gas flows can be maintained less than $0.1{ }^{\circ} \mathrm{C}$.

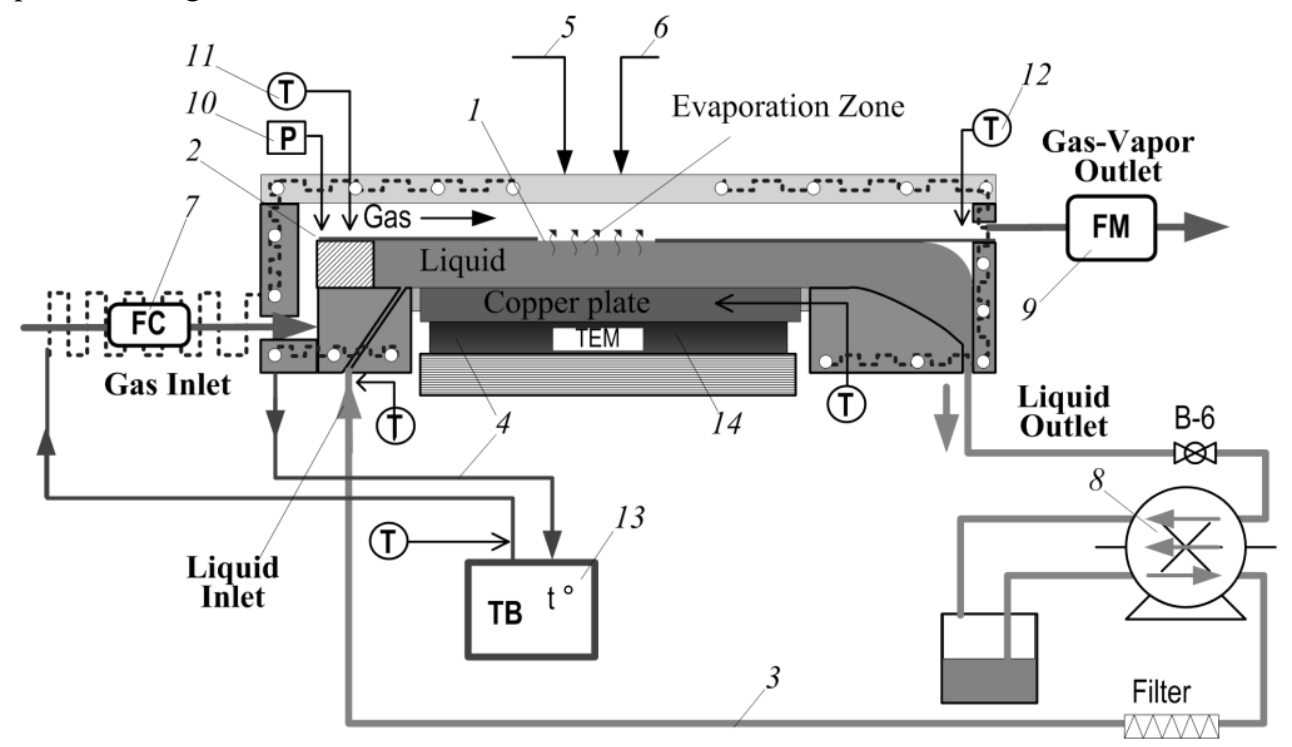

Figure 1. A schematic view of the experimental rig: 1 - test cell; 2 - gas supply circuit; 3 - liquid supply circuit; 4 - thermal stabilization system; 5 - test-and-measurement system; 6 -Schlieren system; 7 - flow controller; 8 - peristaltic pump; 9 - flow meter; 10 - pressure sensor; 11 - gas temperature sensor; 12 - gas-vapor mixture temperature sensor; 13 - thermostatic bath; 14 -Peltier thermoelectric module.

View and general arrangement of the test cell is provided in Fig. 2. Sizes of the gas channel are $3 \times 40 \mathrm{~mm}$ (depth $\times$ width). The liquid chamber has a width of $40 \mathrm{~mm}$ and a variable height from 1 to $10 \mathrm{~mm}$. The upper wall of the liquid channel is formed by a stainless steel plate with a square cutout $(10 \times 10 \mathrm{~mm})$, where the liquid and gas contact. The liquid is supplied through the liquid nozzle to the liquid chamber. Then passing through the evaporation zone at the interface "gas - liquid" it falls into the drain zone and removed from the test cell and is pumped via the peristaltic pump 8 to the container.

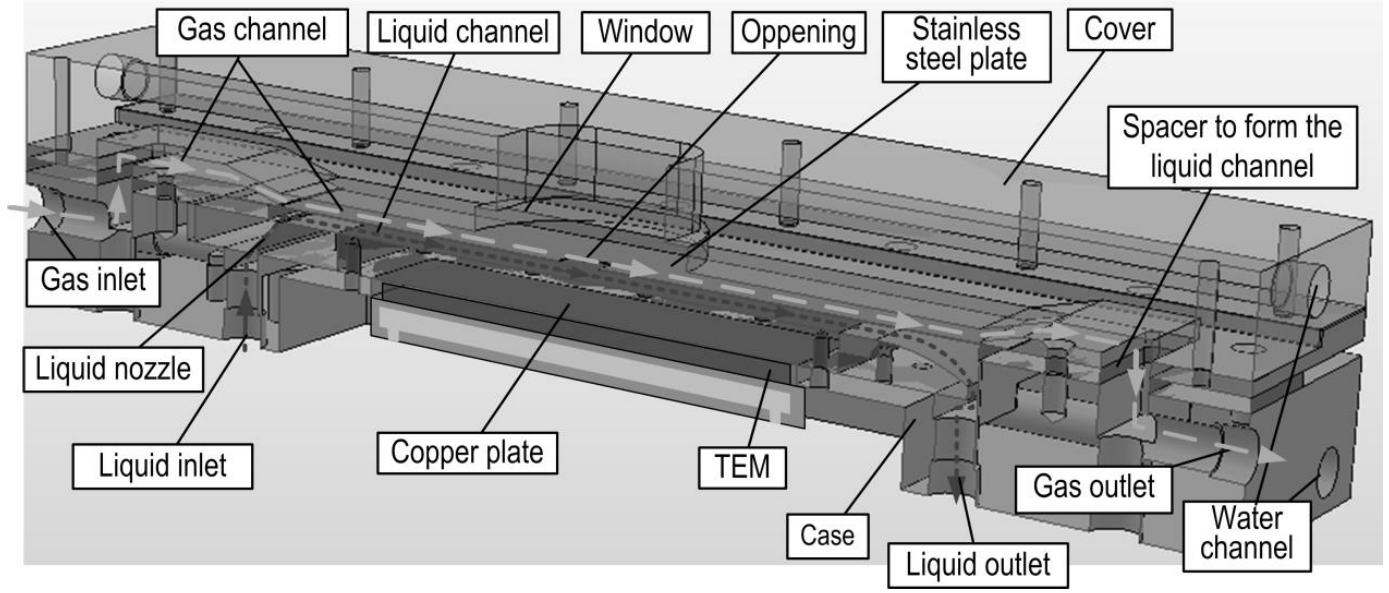

Figure 2. General view of the test cell. 
Thus, there are three zones in the gas channel, see Fig. 3: the inlet diverging zone, where height of the channel increases from $1 \mathrm{~mm}$ to $3 \mathrm{~mm}$ in $80 \mathrm{~mm}$ length; the middle constant-thickness zone of height $3 \mathrm{~mm}$ and of $120 \mathrm{~mm}$ length; the outlet converging zone, where height of the channel reduces from $3 \mathrm{~mm}$ to $1 \mathrm{~mm}$ in $80 \mathrm{~mm}$ length. Due to this geometry of the channel a uniform distribution of the gas flow in the middle zone is achieved.

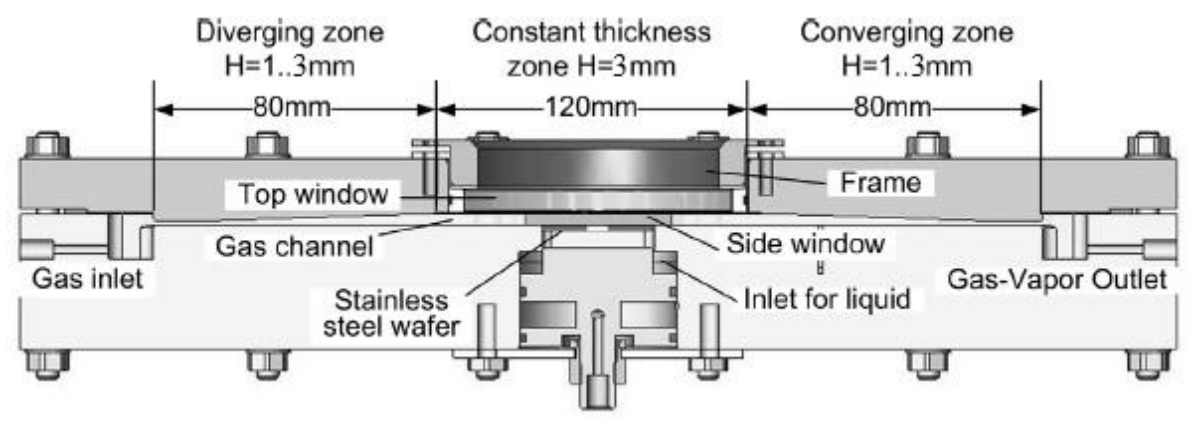

Figure 3. Longitudinal cross section of the test cell.

Schlieren system allowing to determine the curvature of the surface of the liquid layer is used for flatness control of the gas-liquid interface in the test cell. Different states of the gas-liquid interface are shown in Fig. 4.

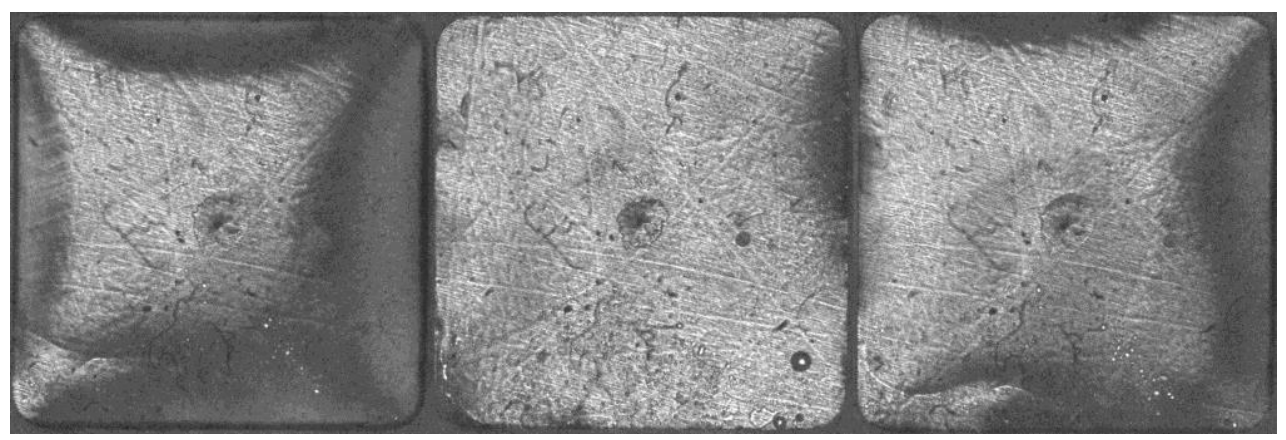

(a) (b)

(c)

Figure 4. Flatness control of the gas-liquid interface: (a) Underfilled; (b) Flat and (c) Overfilled.

The evaporation mass flow rate is determined in the experiment by two methods approved for such problems [9]. The first method is based on evaluation of the average liquid flow in the test cell in order to keep the total liquid volume constant during the evaporation process and planar interphase boundary. The second method is to measure the difference between the mass flow rate of gas at the inlet of the test cell and at the outlet (the gas-vapor mixture).

The gas flow entering the test cell was kept constant $(500 \mathrm{ml} / \mathrm{min})$ in a series of experiments. Layer of liquid (ethanol, GOST R 51723-2001) with a thick of $3 \mathrm{~mm}$ was stationary, surface evaporation was $100 \mathrm{~mm}^{2}$. Equality of liquid layer and gas temperatures has been measured during the experiment $\left(\mathrm{t}_{\mathrm{l}}=\mathrm{t}_{\mathrm{g}}=\mathrm{T}\right.$ from $20^{\circ} \mathrm{C}$ to $\left.40^{\circ} \mathrm{C}\right)$.

\section{Results and discussion}

Dependency of the evaporation flow rate on the temperature in logarithmic coordinates is plotted in Fig. 5. As one can see in Fig. 5 the evaporation flow rate is increased in non-linear form and described by an exponential function:

$$
Q_{l}=C \cdot T^{m}
$$


where $Q_{l}$ - evaporation flow rate of liquid, $\mathrm{kg} /\left(\mathrm{m}^{2} \cdot \mathrm{s}\right) ; C$ - constant; $T$ - temperature of the liquid and gas, ${ }^{\circ} \mathrm{C} ; m$ - an exponent.

Eq. (1) describes the dependence of the evaporation rate from the liquid and gas temperatures. Power $\mathrm{m}$ is found of $m=\operatorname{tg}(\alpha)$, where $\alpha$ - slope of the curve.

The liquid temperature is directly proportional to the average kinetic energy of the molecules. Therefore with increasing of temperature the number of molecules having sufficient kinetic energy in order to break away from the liquid surface increases, therefore, the evaporation flow rate increases.

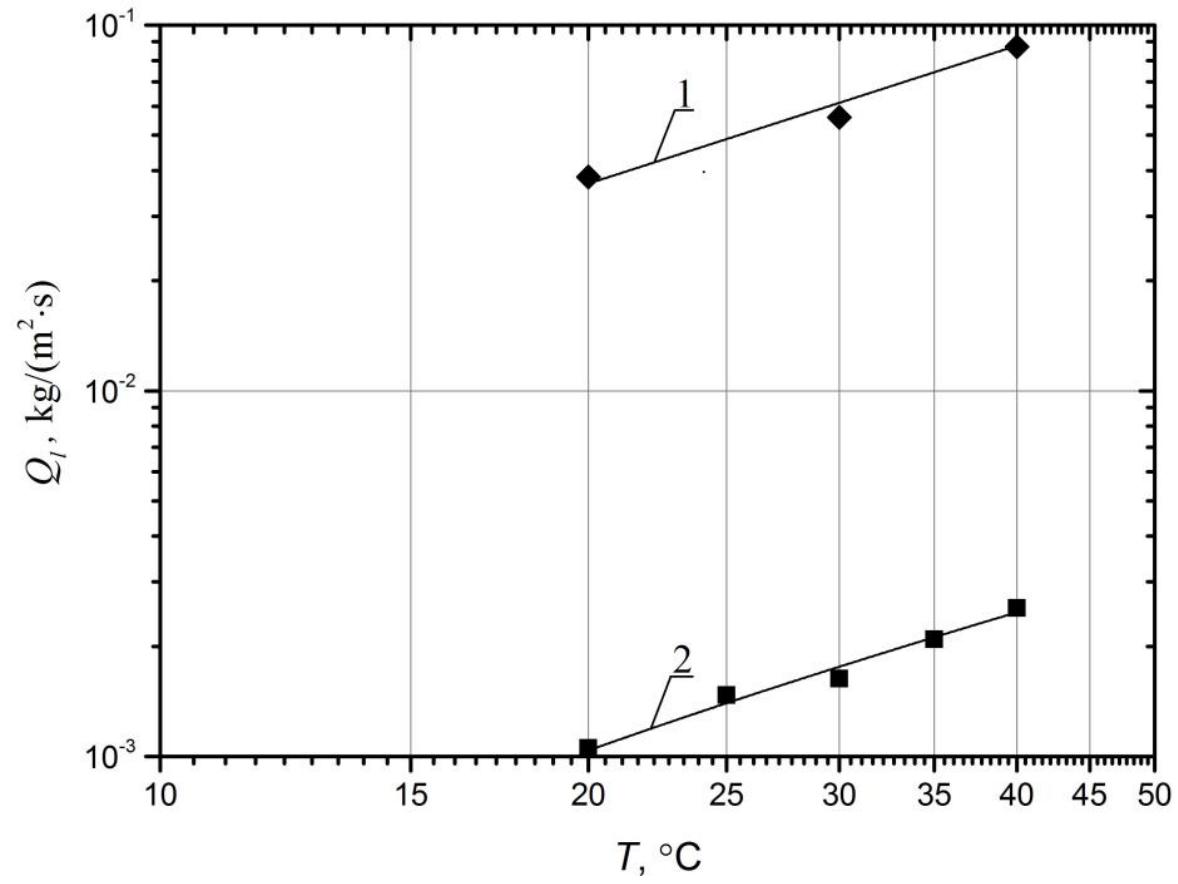

Figure 5. Evaporation flow rate versus the gas and liquid temperature. Working liquid, gas: 1 HFE-7100, nitrogen (99.8\%) [9]; 2 - ethanol (95\% part by volume), air.

Similar experiments were carried out in [9], as a stationary liquid layer they used hydrofluoroether mixture HFE-7100, as a parallel moving gas flow - nitrogen. The results of the evaporation flow rate obtained in [9] are shown in Fig.5. (curve 1). It should be noted that the variation range of the nitrogen velocity in [9] was of 0.003 to $0.16 \mathrm{~m} / \mathrm{s}$, the air velocity in the experiment was equal $\approx 0.06 \mathrm{~m} / \mathrm{s}$.

According to the analysis of Fig. 5 it was found that the angle of the two curves is practically the same. However, the curve 1 is above the curve 2, it can be concluded that constant C (Eq.1) depends on the thermal parameters of the liquid and gas. It is known that the latent vaporization heat of the liquid HFE-7100 to 8 times greater than of ethanol.

\section{Conclusions}

Thus systematic experimental measurements of the average evaporation flow rate depending on the temperature of gas and liquid have been executed. It was found that there is an influence of this parameter on the evaporation rate and convection in the liquid layer. The dependence of the evaporation flow rate from the temperature is nonlinear. The experimental results are compared with existing data.

The work was realized within the research state assignment "Science" (Code of Federal Target Scientific and Technical Program 2.1410.2014). 


\section{References}

[1] O.A. Kabov, Yu.O. Kabova, V.V. Kuznetsov. Doklady Physics, 57, 405 (2012)

[2] E. V. Rebrov. Theoretical foundations of chemical engineering, 44, 355 (2010)

[3] E.A. Chinnov, O.A. Kabov. High Temperature, 44, 773 (2006)

[4] O.A. Kabov. Dissertation, Novosibirsk, 1999

[5] Q.C. Bi, T.S. Zao. Int. J. Multiphase Flow, 27, 561 (2001)

[6] S.M. Ghiaasiaan. Cambridge University, 2007

[7] E.Ya. Gatapova. Dissertation, Novosibirsk, 2005

[8] V.V. Kuznetsov, V.K. Andreev. Thermophysics and Aeromechanics, 20, 17 (2013)

[9] Y. Lyulin, O. Kabov. Int. J. Multiphase Flow, 70,599 (2014)

[10] O.N. Goncharova, O.A. Kabov. Doklady Physics, 54, 242 (2009) 